SITTI ASMAH HASSAN, Ph.D. ${ }^{1}$

(Corresponding Author)

E-mail: sasmah@utm.my

NICK HOUNSELL, Ph.D. ${ }^{2}$

E-mail: N.B.Hounsell@soton.ac.uk

BIRENDRA P. SHRESTHA, Ph.D. ${ }^{3}$

E-mail: Birendra.Shrestha@tfl.gov.uk

1 Department of Geotechnics and Transportation

Faculty of Civil Engineering, Universiti Teknologi Malaysia

81310 Skudai, Johor, Malaysia

2 Faculty of Engineering and the Environment

University of Southampton, Boldrewood Innovation

Campus, Southampton SO16 7QF, UK

${ }^{3}$ Transport for London,

Road Space Management Directorate

197 Blackfriars Road, London SE1 8NJ, UK
Safety and Security in Traffic

Preliminary Communication

Submitted: 2 Aug. 2016

Accepted: 21 June 2017

\title{
INVESTIGATING THE APPLICABILITY OF UPSTREAM DETECTION STRATEGY AT PEDESTRIAN SIGNALISED CROSSINGS
}

\begin{abstract}
In the UK, the Puffin crossing has provision to extend pedestrian green time for those who take longer to cross. However, even at such a pedestrian friendly facility, the traffic signal control is usually designed to minimise vehicle delay while providing the crossing facility. This situation is rather contrary to the current policies to encourage walking. It is this inequity that has prompted the need to re-examine the traffic control of signalised crossings to provide more benefit to both pedestrians and vehicles. In this context, this paper explores the possibility of implementing an Upstream Detection strategy at a Puffin crossing to provide a user friendly crossing. The study has been carried out by simulating a mid-block Puffin crossing for various detector distances and a number of combinations of pedestrian and traffic flows. This paper presents the simulation results and recommends the situations at which Upstream Detection would be suitable.
\end{abstract}

\section{KEY WORDS}

pedestrian crossing; Puffin signal control; simulation; VISSIM;

\section{INTRODUCTION}

Walking is getting more attention as a sustainable transport mode because of its environmental friendliness and health benefits [1, 2]. Local authorities are increasingly providing pedestrian facilities to encourage walking. For example, pedestrian crossings are key facilities in busy urban streets to help pedestrians cross traffic streets safely and efficiently. In the urban areas of most large cities, there is intensive interaction between pedestrian and motorised traffic around the activity of street crossings [3, 4]. A pedestrian crossing can take many forms, ranging from 'informal' facilities, such as pedestrian 'refuges' in the middle of single carriageway roads, to 'formal' facilities such as the Zebra crossing and various forms of signalised pedestrian crossing. Safe and comfortable facilities are two very essential elements that encourage pedestrians to travel on foot. With the increase in traffic signal installations in most towns and cities, signal control has become an integral component of pedestrian crossing facilities. With the allocation of a clear right-of-way in the form of a green light, signal controlled crossings are more user-friendly for pedestrians who feel intimidated by the road traffic. Pedestrian Light Controlled Crossing - Pelican [5] and Pedestrian User-Friendly Intelligent Crossings - Puffin [6] are the examples of such signalised pedestrian crossing facilities installed in the UK. Among them, the Puffin is the most user-friendly signalised pedestrian crossing which has a provision to extend pedestrian green time for those who take longer to cross - e.g. older people and people with reduced mobility.

Even at such pedestrian-friendly facilities, the traffic signal control is usually designed to minimise vehicle delay whilst also providing the crossing facility. Usually, vehicles are the primary objective in improving traffic system performance. At signalised crossings, pedestrians have received far less attention than other modes of travel, particularly compared with motorised vehicles [7, 8, 9]. For example, pedestrians are often only given an 'invitation to cross' (the 'green man') after traffic detection has confirmed that this can be performed without significantly delaying general traffic, even if this results in a longer waiting time for 
pedestrians. This could result in the safety consequences as revealed by Hamed [10] that pedestrians are willing to take a higher risk in crossing the road if they have a longer waiting time. This often leads to an inequity in the facilities provided for these two groups of road users, with delays to pedestrians that often greatly exceed delays to traffic at the same facility. This situation is rather contrary to the current policies to encourage walking and could lead to reductions in walking as a mode of choice. It is this inequity that has prompted the need to re-examine the traffic control of signalised crossings to provide more benefit to road users, both pedestrians and vehicles. There are a number of reasons why walking is important in transport nowadays. Encouraging walking could not only reduce the car dependency, it also promotes a healthier lifestyle for pedestrians [11, 12, 13]. A focus on improving environmental quality not only helps the quality of life but can also make people value walking positively compared to other modes of transport. Walking as well as cycling is a mode of travel that does not produce any emissions and pollutions to the environment. Walking is seen as one of the alternative exercises that could bring benefit to health and environment and is also accepted as the cheapest mode of transport. Walking is the only mode of travel that does not cost anything and does not impose any cost to society.

In this context, this paper explores the possibility of implementing Upstream Detection strategy at a Puffin crossing to provide user-friendly crossing facility with optimum benefits to both pedestrians as well as vehicles.

\section{UPSTREAM DETECTION STRATEGY AT PUFFIN CROSSINGS}

The Puffin is a pedestrian signal-controlled facility developed to provide improved operation for pedestrians and to reduce delay for both drivers and pedestrians. Puffin uses pedestrian detectors, both for the crossing zone (on-crossing detectors) and for the waiting area on the footway (kerbside detectors) as shown in Figure 1.

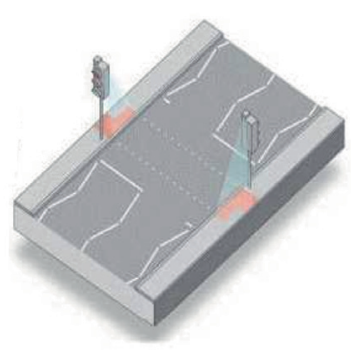

a) Kerb

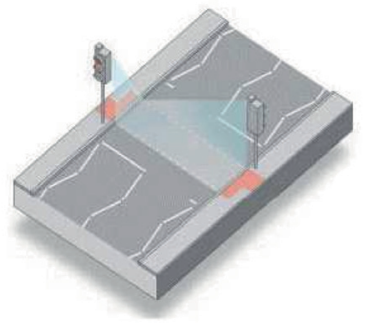

b) On-crossing

Figure 1 -Puffin crossing with pedestrian detectors

Kerbside detectors and on-crossing detectors are used in Puffin crossing as shown in Figure 1. The kerbside detection is used to monitor if pedestrians are present and cancel demands when pedestrians cross in gaps. The on-crossing detection is used to automatically vary the length of the pedestrian period, giving pedestrians the time they need to cross. This is useful when there are large numbers of pedestrians or slow moving pedestrians are crossing.

Pedestrian signals are positioned on the near side of the road (normally mounted on the primary pole on the approach to the crossing) to allow them to watch approaching traffic, while keeping the signal in their field of view. This is particularly helpful for visually impaired people using crossings who cannot clearly discern signals mounted across the road. The use of a steady red signal, similar to traffic displays at junction traffic signals displayed to drivers, reduces the risk of driver confusion. This also gives pedestrians (particularly older and disabled people) a greater sense of protection (compared with a pelican crossing which uses 'Flashing Amber'). This also reduces potential aggressive driver behaviour during flashing amber.

The aim of the Upstream Detection scenario is to minimise the pedestrian delay time without a major disbenefit to vehicular traffic. The principle of Upstream Detection is to provide an earlier activation of the pedestrian stage (pre-arrival detection) with the key features of modern signal control in the UK, which are MOVA and SCOOT $[15,16]$. The underlying principle of the Upstream Detection strategy is the same as standard Puffin, except that it has an extra detection (push button) upstream of the crossing. Figure 2 below shows an illustration of Upstream Detection at signalised crossings.

With Upstream Detection scenario shown in Figure 2, pedestrians can register their demand earlier at an upstream location (x metres distance), rather than having to arrive at the kerbside area to activate the demand. The principle of this new control strategy is similar to the installation of a vehicle detector at the upstream location of a junction to provide earlier activation of the signal control. By activating pedestrian

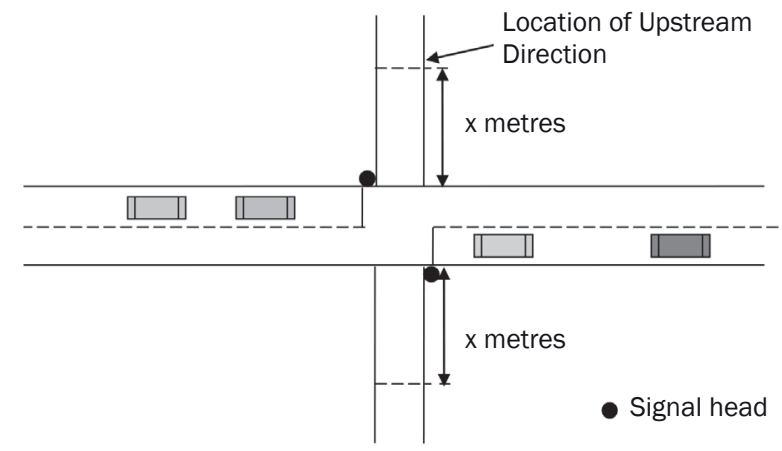

Figure 2 - Upstream Detection scenario 
demand earlier, it is expected to reduce the pedestrian waiting time at the kerbside without disturbing the vehicle flow.

Even though the Upstream Detection concept is straightforward, more exploration is needed to address the issue like: what happens if the pedestrian green is not activated at the time pedestrian arrival? Whether there should be kerbside detection check to make sure the pedestrian/s is/are still there to cross (in Puffin control, a pedestrian demand is cancelled if there is no pedestrian waiting on the kerbside)? What is the role of kerbside push button? To explore all these implementation issues in more detail taking account of pedestrian behaviour response to the changed strategy, the study was carried out by modelling a mid-block crossing using the VISSIM micro-simulation model.

\section{SIMULATION MODELLING OF THE UPSTREAM DETECTION STRATEGY}

For this study a calibrated Puffin model by Hassan et al. [17] was used as a Base Case scenario in the signal control of road networks. The model was developed further to simulate the Upstream Detection strategy at Puffin crossings. The use of a hypothetical model allows full control and greater flexibility over various traffic, pedestrians and signalling conditions.

For the initial modelling purpose, the data on vehicle speed and pedestrian behaviour were collected at historical video at Market Street, Manchester. The characteristics of the signalised pedestrian crossing used in the model, as observed at the signalised crossing in Market Street, Manchester are as follows:

- Single carriageway with $3.5 \mathrm{~m}$ wide lanes in both directions.

- Traffic composition as 95\% cars, 3\% HGVs and 2\% buses.

- The desired speed distribution for all vehicle classes as $30.0 \mathrm{~km} / \mathrm{h}-48.0 \mathrm{~km} / \mathrm{h}$

- The desired speed distribution for pedestrians as $1.9 \mathrm{~km} / \mathrm{h}-7.2 \mathrm{~km} / \mathrm{h}$

- Pedestrian crossing behaviour as follows: $64 \%$ of pedestrians press the push button and obey the signal indication; $6.5 \%$ of pedestrians press the push button but gap-cross when there is an opportunity; and $29.5 \%$ ignore the signal control and gap-cross in vehicle traffic when there is an opportunity. The fixed aspects of the signal timings were 2 seconds of red-amber, followed by 3 seconds of amber and pedestrian green was 6 seconds long, followed by the variable red-clearance period.

Upon arrival at the crossing location, the pedestrian is exposed to two types of gaps; safe or unsafe. Safe gaps can be thought of as a combination of large gaps in moving traffic as well as gaps created by yielding drivers. The pedestrian then makes a decision to accept or reject the gap. To represent the interaction between pedestrians and vehicles in VISSIM, the critical gap is the most important parameter. Simply stated, a pedestrian in VISSIM will cross, on the average, when a gap occurs that is greater than their critical gap. Otherwise, they will wait until an acceptable gap occurs. A pedestrian crossing decision can be described as a function of the pedestrian critical lag time. A 'lag' is the time between a pedestrian arrival at the crossing and the arrival of the next conflicting vehicle at the crossing (Schroeder and Rouphail, 2007). The pedestrians will cross if the lag time to the next vehicle arrival is greater or equal to the critical lag time. Pedestrians were coded to accept a minimum 6 seconds gap for two-way traffic.

At this stage, upstream pedestrian detection was assumed to occur through conventional push button(s) system, with the pedestrian demand registered some distance/time upstream of the crossing. If the strategy proves beneficial, a later stage in the research could be to consider other means of registering upstream pedestrian demand (e.g. personal Bluetooth communication, wider image processing, etc.).

In this study, the Upstream Detection strategy at Puffin crossing was modelled in VISSIM using Vehicle Actuated Program (VAP). In the model, any vehicle detected within 4 seconds of the leading vehicle will extend the green time by 4 seconds. In this new signal control strategy, the pedestrian demand is sent to the signal controller when Upstream Detection is activated by a pedestrian during the vehicle stage. Once a pedestrian demand is registered, two traffic conditions are checked before changing the traffic signal to a pedestrian phase: (a) the minimum green for vehicles, and (b) gap-out events or the maximum green for vehicles. If the first requirement is satisfied (the minimum green time has expired), then the next requirement is gap-out or max-out events. If either of these requirements is satisfied (i.e. there is a gap of more than 4 seconds between vehicles or the maximum green for vehicles has been reached), then the pedestrian stage can be given instantly to pedestrians. It is assumed that, if all of these requirements are satisfied upon the activation of Upstream Detection, the pedestrian green would start in 4 seconds of the demand. This principle is further illustrated in Figure 3.

Figure 3 shows an example where detection could extend the vehicle green time up to its maximum of 30 seconds. At 19 seconds, Upstream Detection is activated by a pedestrian. The first requirement is satisfied (more than the vehicle minimum green time, which is 7 seconds, has elapsed). Here, the second requirement (gap-out or max-out event) is also satisfied with a gap-out event at 19 seconds (there is a gap of 4 seconds or more since the last vehicle was detected). Therefore, the change of stage occurs upon the activation of Upstream Detection so that the pedestrian stage is started at 23 seconds. However, 


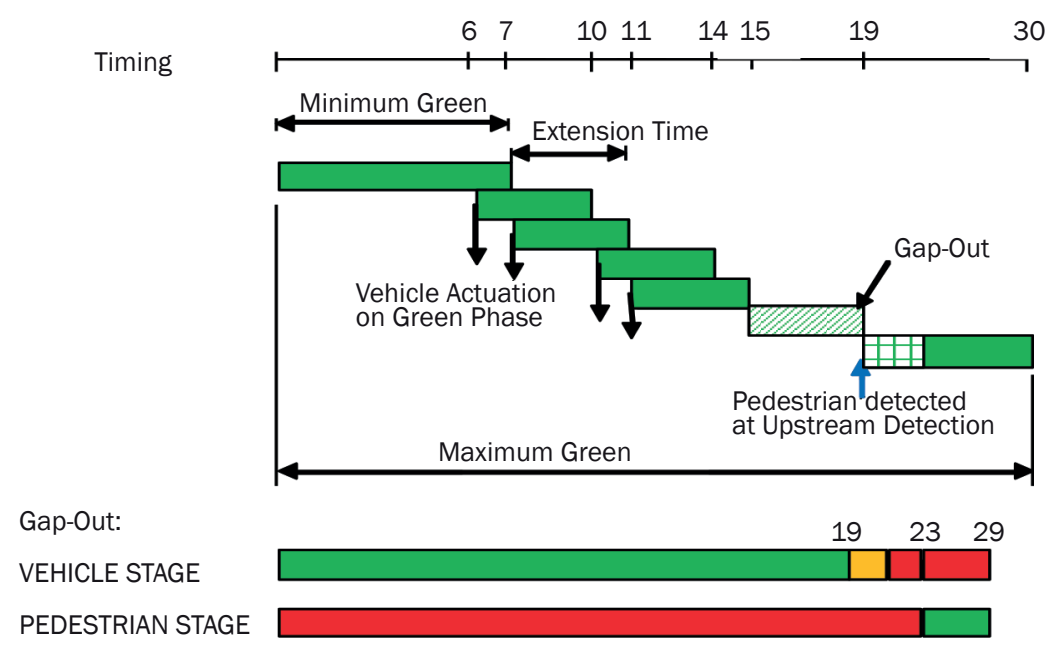

Figure 3 - The principle of Upstream Detection

if the inter-stage does not occur in the first 4 seconds, the pedestrian presence at the kerbside is also checked. This is to cancel the demand if there is no pedestrian waiting on the kerbside.

Using the model, the impact of Upstream Detection was explored for the following two scenarios: Case 1: Different Upstream Detection Locations, and Case 2: Different Vehicle and Pedestrian Flow Combinations.

These two scenarios were developed to test the applicability of this Upstream Detection strategy under various situations.

\section{RESULTS AND DISCUSSION}

\subsection{Scenario 1: Different locations of Upstream Detection}

The location of Upstream Detection is very important for the efficiency of the Puffin crossing. If it is very close to the kerbside, it is less effective and if very far the pedestrian green could be underutilised and could result in more delays to both pedestrian and vehicles. Theoretically, an upstream detector should be at a distance equal to the inter-green time used. This makes sure that pedestrian green is activated when the pedestrian activating the upstream detector arrives at the kerbside. However, the optimum detector distance could be different if the pedestrian as well as vehicle delays are taken into account. Therefore, three pre-determined distances of Upstream Detection: 3 metres, 5 metres and 10 metres were modelled to determine 'the best distance from those tested' of Upstream Detection on the basis of the delay experienced by vehicles and pedestrians.

Based on a simple calculation using the $15^{\text {th }}$ percentile speed $2.7 \mathrm{~km} / \mathrm{h}$ and 4 seconds intergreen time, the initial location of Upstream Detection is 3 metres upstream of the crossing as shown in Figure 2.
The $15^{\text {th }}$ percentile speed is the speed below which $15 \%$ of pedestrians would walk.

With a walking speed range $1.9 \mathrm{~km} / \mathrm{h}$ to $7.2 \mathrm{~km} / \mathrm{h}$ and 3 metres distance of Upstream Detection, the pedestrian arrival time range on the pedestrian crossing is between 1.5 seconds and 5.7 seconds. There are $85 \%$ of pedestrians who would arrive in 1.5 - 4 seconds. And the remaining $15 \%$ of pedestrians would arrive in $4-5.7$ seconds. Based on the walking speed of $1.2 \mathrm{~m} / \mathrm{s}$ (walking speed used in designing pedestrian facilities at signalised crossings) and the intergreen time of 4 seconds, the distance of Upstream Detection was 4.8 metres, hence the option of using 5 metres in this study. 10 metres was chosen arbitrarily as double the 5-metre distance.

In this scenario traffic flows and pedestrian flows modelled were $700 \mathrm{veh} / \mathrm{h}$ and $300 \mathrm{ped} / \mathrm{h}$ (for both directions), respectively. There were 700-300 arbitrarily chosen based on the initial observation of traffic flow at Market Street, Manchester. Then, different traffic flow combinations were explored to see the impact of different traffic flow combinations on the performance of the Upstream Detection. Figure 4 shows the results of vehicle delays and pedestrian delays for the base case (standard Puffin crossing) and three different

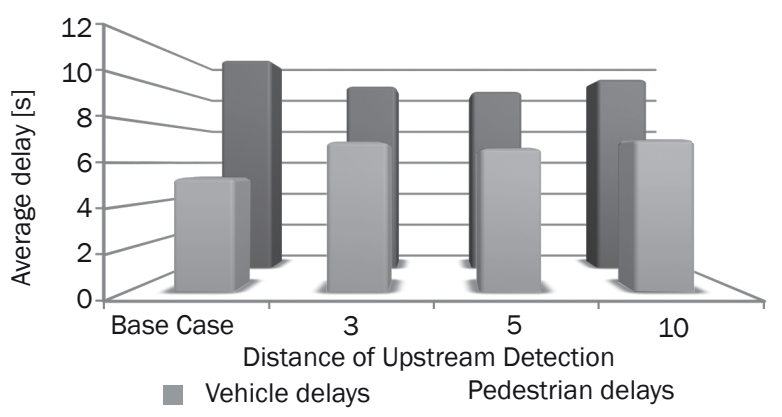

Figure 4 - Influence of detector locations on vehicle and pedestrian delays 
Upstream Detection locations: 3 metres, 5 metres and 10 metres in advance of the crossing.

Figure 4 shows that Upstream Detection increased the delay to vehicles in all cases and reduced the delay to pedestrian in all cases. This was expected because the Upstream Detection strategy causes more frequent pedestrian phases compared to the base case. Thus, it caused frequent stopping of vehicle movement, hence the increase in vehicle delay, and it caused frequent pedestrian phases to be given to pedestrians, hence the reduction in pedestrian delay.

By considering both vehicle and pedestrian delays in the analysis, it was found that 5 metres gave the lowest delay to both vehicles and pedestrians, so this distance was used in the next modelling stages.

\subsection{Scenario 2: Different traffic flow conditions}

The impact of Upstream Detection strategy could vary for different levels of vehicle flow and pedestrian flow combinations. For example, it is possible that, at high pedestrian flows and low traffic flows, the signals may run predominantly on a minimum green for traffic. In that case, signal timings and vehicle or pedestrian delays would be unaffected by further increases in pedestrian flow. Therefore, the impact of the Upstream Detection strategy was examined with twelve combinations of vehicle and pedestrian flows, as shown in Table 1. The vehicle flows and pedestrian flows are for both directions.

All these combinations of vehicle and pedestrian flows were simulated with and without the Upstream Detection strategy. In the case of Upstream Detection, the upstream detector was placed 5 metres upstream of the kerbside as determined in the earlier section. Each combination was simulated for 10 runs each with unique random seeds to minimise the effect of random variations in the vehicles and pedestrian flows. Figure 5 shows the change in the number of signal cycles with and without Upstream Detection strategy for all combinations.

Table 1 - Vehicle and pedestrian flow combinations

\begin{tabular}{|c|c|}
\hline Vehicle flow [veh/h] & Pedestrian flow [ped/h] \\
\hline \multirow{3}{*}{100} & 100 \\
\hline & 300 \\
\hline & 500 \\
\hline \multirow{3}{*}{300} & 100 \\
\hline & 300 \\
\hline & 500 \\
\hline \multirow{3}{*}{700} & 100 \\
\hline & 300 \\
\hline & 500 \\
\hline \multirow{3}{*}{1,408} & 100 \\
\hline & 300 \\
\hline & 500 \\
\hline
\end{tabular}

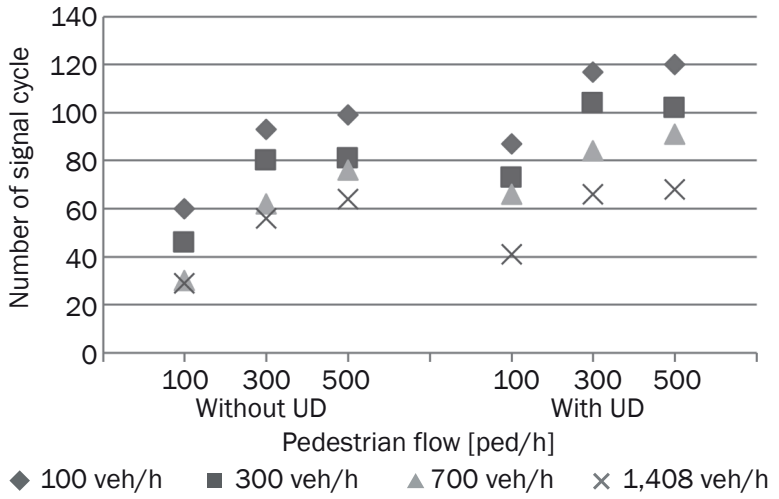

Figure 5 - Change in the number of signal cycles with Upstream Detection (UD)

As expected, Figure 5 shows that an increase in pedestrian demand increases the number of signal cycles. In contrast, increasing vehicle volumes reduces the number of signal cycles to cater for the higher vehicle demand. The figure also shows that there are more signal cycles with the Upstream Detection in comparison to no Upstream Detection. Upstream Detection provided an additional earlier opportunity to request the pedestrian green phase, 5 metres in advance of the crossing. Therefore, the pedestrian stage was called more frequently in the Upstream Detection case. As a result, vehicle green time is reduced in the case of Upstream Detection which is shown in Figure 6.

It is evident from Figure 6 that, at high levels of pedestrian and vehicle flow (1,408 veh/h and 500 ped/h), changes in the average green time are smaller - 30 seconds (no Upstream Detection) and 26 seconds (with Upstream Detection). However, at lower vehicle flows (100 veh/h and 300 veh/h), the implementation of Upstream Detection caused a larger reduction in average green time (by approximately half in many combinations). This is because, at a lower vehicle flow (100 veh/h and $300 \mathrm{veh} / \mathrm{h}$ ), the gap-out requirement needed for a change in the stage would be more easily satisfied.

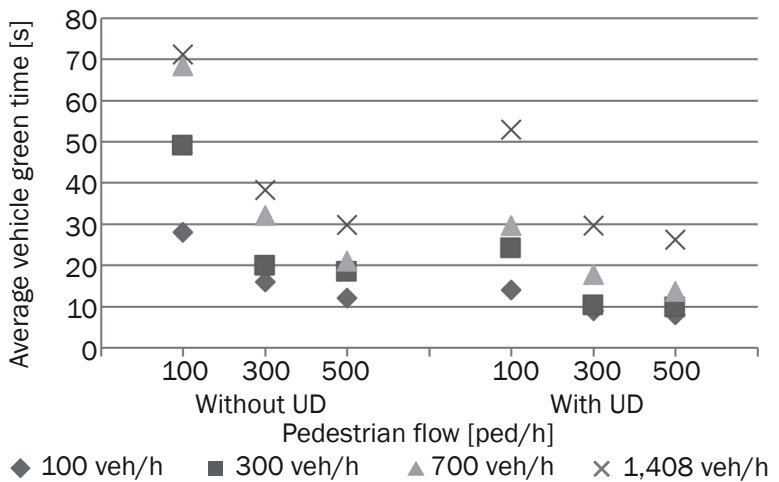

Figure 6 - Change in the average vehicle green time with Upstream Detection (UD) 
Figure 7 shows the vehicle delay results for both with and without Upstream Detection cases for all twelve combinations.

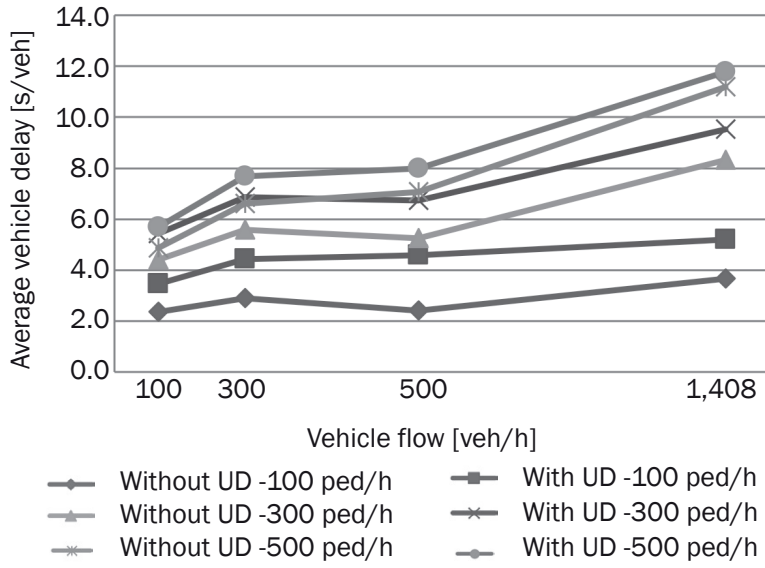

Figure 7 - Impact of Upstream Detection (UD) on vehicle delays

Figure 7 shows that for all the combinations, Upstream Detection resulted in a higher delay to vehicles compared to without Upstream Detection. This is due to more frequent pedestrian calls, which resulted in more frequent stage changes and reduced green time for vehicles. In addition, as expected, Figure 7 shows that vehicle delay increased steadily with an increase in the volume of pedestrian and/or vehicle traffic. The change in vehicle delay with the Upstream Detection was relatively smaller in the case of higher pedestrian flows (500 ped/h) than lower pedestrian flows. At a higher pedestrian flow (500 ped/h), the higher number of stage changes without Upstream Detection resulted in a small change in vehicle delay with a limited increase in the stage changes with Upstream Detection. The resulting pedestrian delays for twelve combinations are shown in Figure 8.

In contrast to Figure 7, as expected, Figure 8 shows that the implementation of Upstream Detection reduced pedestrian delay in all twelve combinations.

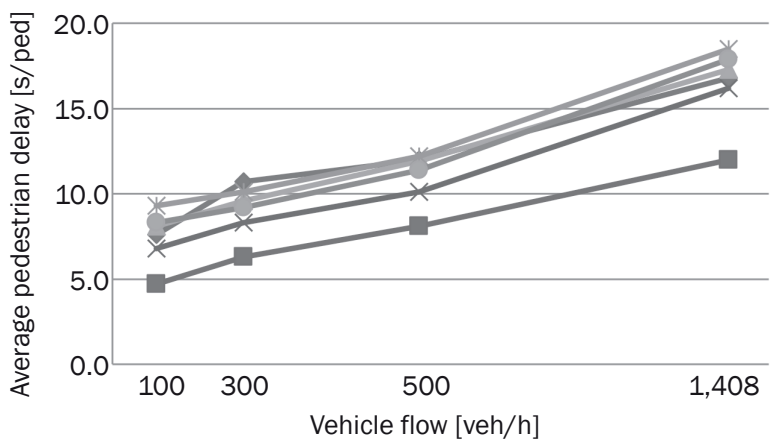

$\because$ Without UD $-100 \mathrm{ped} / \mathrm{h} \quad \rightarrow$ With UD $-100 \mathrm{ped} / \mathrm{h}$

$\because$ Without UD $-300 \mathrm{ped} / \mathrm{h} \simeq$ With UD $-300 \mathrm{ped} / \mathrm{h}$

* Without UD $-500 \mathrm{ped} / \mathrm{h} \rightarrow$ With UD $-500 \mathrm{ped} / \mathrm{h}$

Figure 8 - Impact of Upstream Detection on vehicle flow
The level of reduction is much larger at low level of pedestrian flow (100 ped/h) than high level of pedestrian flow.

Based on the observation of these simulation results, a summary of potential effects of Upstream Detection is given in Table 2 .

Table 2 - Potential effects of Upstream Detection

\begin{tabular}{|l|c|c|c|}
\hline $\begin{array}{r}\text { Pedestrian flow } \\
\text { Vehicle flow }\end{array}$ & $\begin{array}{c}100 \\
\text { [ped/h] }\end{array}$ & $\begin{array}{c}300 \\
\text { [ped/h] }\end{array}$ & $\begin{array}{c}500 \\
\text { [ped/h] }\end{array}$ \\
\hline \hline $100 \mathrm{veh} / \mathrm{h}$ & $\sqrt{ }$ & $\sqrt{ } \sqrt{ }$ & $\sqrt{ } \sqrt{ }$ \\
\hline $300 \mathrm{veh} / \mathrm{h}$ & $\sqrt{ }$ & $\sqrt{ }$ & $\sqrt{ }$ \\
\hline $700 \mathrm{veh} / \mathrm{h}$ & $\mathrm{xx}$ & $\mathrm{x}$ & $\mathrm{x}$ \\
\hline $1,408 \mathrm{veh} / \mathrm{h}$ & $\mathrm{xx}$ & $\mathrm{x}$ & $\mathrm{x}$ \\
\hline
\end{tabular}

Key: $\sqrt{ }$ - possible overall benefit, $\sqrt{ } \sqrt{ }$ - probable overall benefit, $x$ - possible overall disbenefit, $x x$ - probable overall disbenefit

Table 2 shows that the implementation of Upstream Detection has a clear benefit at a lower vehicle flow (100 veh/h), where the flow of people in vehicles exceeds the flow of pedestrians. There was a small positive impact in travel time savings at $300 \mathrm{veh} / \mathrm{h}$ at all levels of pedestrian flow. However, at a higher vehicle flow, it caused a larger increase in the total delay time.

\section{DISCUSSION}

Through the simulation of different locations of upstream detector and different traffic flow combinations, the study has showed that the best upstream detector location from those tested is 5 metres upstream of the crossing and the Upstream Detection is beneficial at sites where vehicle flow is low. Even though the results are promising, there are some issues which need to be considered when implementing in the field.

With Upstream Detection, an extra detector needs to be installed for each arriving point. Depending on the site characteristics, more than one detector may be needed to facilitate pedestrians from different directions. The installation cost of such detectors needs to be considered when implementing the system in the field. Again, naturally, the added Upstream Detection adds complexity to a Puffin system which may increase the maintenance cost, too.

The benefit from Upstream Detection is calculated on the assumption that all pedestrians cross the road at the defined location. However, in reality, some pedestrian may walk sidewise and cross when they find appropriate gap in the traffic flow. This will reduce delays and reduce the benefits from the installation of Upstream Detection.

The results given in the paper are dependent on the assumptions of pedestrian crossing behaviour especially gap crossing. If a site has a very high proportion of gap crossing pedestrians, the benefits from upstream detector will be fewer than given in this paper. 
Apart from these implementation issues, the paper has demonstrated that the efficiency of Puffin crossing could be improved with Upstream Detection in certain situations. It showed that pedestrian delays could be reduced without severely penalising the traffic. As the function of an Upstream Detection is to demand a pedestrian phase early, Upstream Detection should be beneficial in other signalised pedestrian crossing, too. The implementation of such strategy is in the right direction to encourage walking which is the best form of movement in terms of the environment and the health benefits.

\section{CONCLUSIONS}

There are two main types of pedestrian signalised crossings in Britain: Pelican crossings and Puffin crossings. Pelican crossings do not have any pedestrian detection technologies except for the push buttons. On the other hand, Puffin crossings have three different aspects of pedestrian detection - the push button, kerbside detection and on-crossing detection. This study has focused on the Puffin crossing as the "base case'.

This study has taken the Puffin crossing as the 'state-of-the-art' signal-controlled crossing for pedestrians and has explored possible improved control strategies through the development and application of a Puffin simulation model, using VISSIM. In particular, a new strategy - Upstream pedestrian detection has been evaluated using VISSIM.

Two signal control plans were successfully modelled in VISSIM microsimulation model - current operations (the Base Case) and Upstream pedestrian detection. In conclusion, the Upstream Detection strategy had a positive impact compared to the Base Case strategy, but only in specific combinations of vehicle and pedestrian flows.

Upstream pedestrian Detection was identified as potential enhancement at Puffin crossings. The idea of this strategy was to give an earlier detection of pedestrians (i.e. upstream of the crossing) as happens with vehicle detection. With this method, the pedestrian phase can be initiated as early as possible upon receiving the demand from Upstream Detection. Upstream Detection was modelled in the VISSIM microsimulation model by locating additional push button detection further upstream from the crossing and using enhanced pedestrian behaviour logic.

However, the result in this study has a degree of uncertainty in that a pedestrian behaviour logic has had to be assumed which cannot yet be validated (because the strategy does not exist). Also, if policy favours pedestrians over vehicles more than assumed here, then the Upstream Detection strategy would become beneficial over a wider range of vehicle flows. Results from this study have opened up new paths for further work, with a wide range of opportunities including further application or even further development of the model.

\section{ACKNOWLEDGEMENT}

The authors would like to thank the management of Universiti Teknologi Malaysia (Vote: 17H71) for providing the necessary facilities and financial support to support this research.

\section{Dr. SITTI ASMAH HASSAN ${ }^{1}$ \\ E-mail: sasmah@utm.my \\ Prof. Dr. NICK HOUNSELL ${ }^{2}$ \\ E-mail: N.B.Hounsell@soton.ac.uk \\ Dr. BIRENDRA P. SHRESTHA ${ }^{3}$ \\ E-mail: Birendra.Shrestha@tfl.gov.uk \\ ${ }^{1}$ Department of Geotechnics and Transportation Faculty of Civil Engineering, Universiti Teknologi Malaysia 81310 Skudai, Johor, Malaysia \\ 2 Faculty of Engineering and the Environment University of Southampton, Boldrewood Innovation Campus, Southampton SO16 7QF, UK \\ 3 Transport for London, Road Space Management Directorate, 197 Blackfriars Road, London SE1 8NJ, UK}

\section{MENYIASAT KEBOLEHGUNAAN STRATEGI PENGESAN AWAL DI LINTASAN BERLAMPU ISYARAT PEJALAN KAKI}

\section{IKHTISAR}

Di UK, lintasan Puffin mempunyai kemudahan untuk melanjutkan tempoh hijau pejalan kaki kepada mereka yang memerlukan masa yang lebih untuk melintas. Walau pun ia adalah kemudahan yang mesra pejalan kaki, kemudahan melintas biasanya direkabentuk untuk mengurangkan kelewatan masa kenderaan disamping menyediakan kemudahan melintas. Keadaan ini bercanggah dengan polisi semasa yang menggalakkan berjalan kaki. Percanggahan ini mewujudkan keperluan untuk menilai semula kawalan lalulintas di lintasan berlampu isyarat untuk memberikan lebih manfaat kepada kedua-dua pejalan kaki dan kenderaan. Dalam konteks ini, rencana ini meneroka kemungkinan untuk melaksanakan strategi 'Pengesanan Awal' di lintasan Puffin untuk menyediakan lintasan mesra pejalan kaki. Kajian ini telah dijalankan dengan simulasi lintasan Puffin di pertengahan jalan dengan pelbagai jarak pengesan dan gabungan aliran pejalan kaki dan kenderaan. Rencana ini menyediakan keputusan simulasi dan cadangan keadaan di mana strategi 'Pengesan Awal' ini lebih sesuai.

\section{KATAKUNCI}

lintasan pejalan kaki; kawalan isyarat Puffin; simulasi; VISSIM;

\section{REFERENCES}

[1] Southworth M. Designing the Walkable City. Journal of Urban Planning and Development. 2005;131(4):246-257.

[2] Tsukaguchi H, Sugihara S, Vandebona U, Yeh KY. Comparison of Attitudes Toward Walking in Japanese Cities. Journal of the Eastern Asia Society for Transportation Studies. 2007;7:1794-1805. 
[3] Hine J. Pedestrian travel experiences: assessing the impact of traffic on behaviour and perceptions of safety using an in-depth interview technique. Journal of Transport Geography. 1996;4(3):179-199.

[4] Li B. A model of pedestrians' intended waiting times for street crossings at signalized intersections. Transportation Research Part B: Methodological. 2013;51:17-28.

[5] Department for Transport. Local Transport Note 2/95. The Design of Pedestrian Crossings. London; 1995a.

[6] Department for Transport. Traffic Advisory Leaflet 1/01. Puffin Pedestrian Crossing. London; 2001.

[7] Wigan M. Treatment of Walking as a Mode of Transportation. Transportation Research Record 1487. 1995;7-13.

[8] Hunt J, Lyons GD. Enhanced operating strategies to improve pedestrian amenity and safety at midblock signalled pedestrian crossings. Pedestrians, European Transport Conference 1997. Association for European Transport; 1997.

[9] Keegan O, O'Mahony M. Modifying pedestrian behaviour. Transportation Research Part A: Emerging Technologies. 2003;37:889-901.

[10] Hamed MM. Analysis of pedestrians' behavior at pedestrian crossings. Safety Science. 2001;38:63-82.

[11] Halden D. Civilising Pedestrian Crossing Facilities. Streets for the $21^{\text {st }}$ Century I, European Transport
Conference 2005. Association for European Transport; 2005.

[12] Heuman D, Buchanan P. Valuing Walking Evaluating Improvements to the public realm. Streets for the 21st Century I, European Transport Conference 2005. Association for European Transport; 2005.

[13] Ishaque MM, Noland RB. Micro-Simulated Comparisons of Alternative Signalized Pedestrian Crossings. TRB 85th Annual Meeting 22 - 26 January, 2006, Washington, D.C.: TRB, National Research Council; 2006.

[14] Department for Transport. Traffic Advisory Leaflet 1/02. The Installation of Puffin Pedestrian Crossings. London; 2002.

[15] Department for Transport. Traffic Advisory Leaflet 4/95. The SCOOT Urban Traffic Control System. London; 1995b.

[16] Department for Transport. Traffic Advisory Leaflet 3/97. The MOVA signal control system. London; 1997.

[17] Hassan SA, Hounsel, NB, Shrestha BP. Verification of Puffin Modelling using VISSIM. In special edition on Sustainability Issues in Transportation Engineering, Jurnal Teknologi (Sciences and Engineering). 2013;65(3):81-84. doi: 10.11113/jt.v65.2150. 